\title{
PEMIKIRAN ABRAHAM GEIGER TENTANG AL-QUR`AN (Studi Atas Akulturasi Linguistik, Doktrin Dan Kisah Dalam Al-Qur`an Dari Tradisi Yahudi)
}

\author{
Wendi Parwanto \\ Universitas Islam Negeri Sunan Kalijaga Yogyakarta \\ wendi4september1995@gmail.com
}

Diterima 19 Maret 2019 | Direview 30 April 2019| Diterbitkan 01 Juni 2019

\begin{abstract}
:
Various kinds of orientalist studies on Islam began in the early 19th century, such as studies of the al-Qur'an, hadith, fiqh, and others. One of the orientalist who study Islam from the aspect of the Qur'an is Abrabam Geiger. Geiger said, that there are several aspects of the Qur'an that adopted by Jewish traditions. Based on these reasons, the resecher are interested in studying this theme further. This study is a study of library research, with descriptive-analysis method. The conclusion of this study is that some Muslim scholars acknowledge the influence of Islam from other religions, not only from the linguistic aspect of the Qur'an, but also from the empirical-practical, and Islam comes to renew and modify the traditions of previous religions that are not in accordance with values of Islam.
\end{abstract}

Keywords: Abraham Geiger, Linguistic Acculturation, Doctrine, Story, Jews

\section{Abstrak:}

Berbagai ragam kajian orientelis tentang Islam sudah dimulai sejak permulaan abad ke-19, mulai dari kajian seputar al-Qur`an, hadis, figh, dan lain-lain. Salah satu tokoh orientalis yang mengkaji Islam dari aspek alQur`an adalah Abraham Geiger. Gaiger berpendapat ada beberapa aspek dari al-Qur an yang diadopsi dari tradisi Yahudi. Berdasakan alasan tersebut, maka penulis tertarik untuk mengkaji tema ini lebih jauh. Penelitian ini adalah kajian kepustakaan, dengan metode diskriptif-analisis. Kesimpulan dari kajian ini adalah, beberapa cendikiawan Muslim mengakui adanya keterpengaruhan Islam dari agama lain, bukan hanya dari segi linguistik al-Qur`an saja, namun juga dari sisi empiris-praktis, dan Islam datang untuk memperbaharui dan memodifikasi tradisi dari agama-agama sebelumnya yang tidak sesuai dengan nilai-nilai Islam.

Kata Kunci: Abraham Geiger, Akulturasi Lingusitik, Dokrin, Kisah, Yahudi

\section{Pendahuluan}

Studi ketimuran (oriental studies) yang ditengarai muncul pada abad 19, merupakan suatu studi yang mencakup kajian tentang linguistik, historis dan budaya dari Asia dan Afrika Utara. Kajian-kajian tersebut berdasarkan pada filologi dalam arti yang lebih luas, yaitu kajian-kajian terhadap budaya melalui studi terhadap sumber aslinya, khususnya dari teksteks yang di anggap otoritatif. ${ }^{1}$ Studi ketimuran ini yang kemudian lebih dikenal dengan istilah Orientalisme terus berkembang dan meluas hingga sekarang, kajian mereka banyak meliputi terhadap segala aspek disiplin keilmuan, seperti kajian bahasa Arab, seperti Albert Socin, HL. Fleischer, kajian teks, seperti Theodor Noldeke dan Gustav Flugel, kajian historis, seperti Gustav Weil dan Carl Brockelmann, kajian Agama Islam, seperti Ignaz Goldziher dan Richard Gramlich, kajian hukum Islam, seperti Edward Sachau dan Joseph Schacht, serta kajian-kajian yang lain. Hasil dari kajian-kajian mereka juga banyak memberikan kontribusi terhadap keilmuan baru, dalam studi keislaman. ${ }^{2}$

\section{Barat dan Timur Serta Agama Yahudi}

\section{a. Motivasi Barat Melakukan Kajian Terhadap Timur}

\footnotetext{
${ }^{1}$ Azim Nanji (ed), Peta Studi Islam: Orientlisme dan Arah Baru Kajian Islam di Barat.(Yogyakarta: Fajar Pustaka Baru, 2003). h. 2.

${ }^{2}$ Azim Nanji (ed), Peta Studi Islam: Orientlisme dan Arab Baru Kajian Islam Di Barat. (Yogyakarta: Fajar Pustaka Baru, 2003), h. 33-37.
} 
Upaya-upaya yang dilakukan orientalis dalam mempelajari ketimuran dimotivasi oleh hal-hal berikut ${ }^{3}$ :

1) Dorongan ajaran agama (Gospel)

Sudah diketahui bahwa awal pertama kali bangsa barat yang mengkaji ketimuran berdasarkan keterangan yang ditemukan ialah kalangan pendeta dan misionaris agama. Mereka dengan gigih mengkaji ketimuran bahkan sampai sekarang ini. Dalam kajian islam, mereka gigih mempelajarinya untuk menghuncurkan ajaran ini dan berupaya melakukan distorsi kebenaran yang datang dari dunia islam. Tujuannya agar dunia barat memandang sebagai ancaman bagi agama masihiyyah (kristen) yang mereka anuti sehingga islam tidak berhak untuk menyebar di jagat raya ini.

2) Dorongan kekuasaaan (Glory)

Dengan berakhirnya perang Salib yang dimenangkan oleh kaum Muslimin, tidak membuat putus asa bagi kalangan barat untuk terus menguasai negara-negara timur, khususnya negara-negara Islam. Mereka berupaya keras dengan segala cara agar dapat menundukan negara yang mereka inginkan. Mereka upayakan demi memperoleh kekuasaan dan kejayaan dengan mempelajari negeri jajahan mereka masing-masing baik dari segi akidah, adat istiadat, pola hidup, maupun peninggalan kebudayaannya. ${ }^{4}$

3) Dorongan Bisnis dan Politik (Gold and Politic)

Keingingan memperoleh keuntungan yang sebesar-besarnya, mereka berupaya memperoleh bahan baku yang lebih murah dan menjualnya dengan harga yang tinggi di pasaran sehingga bisa merugikan perusahaan setempat. Mereka pun tidak tanggungtanggung mengeruk kekayaan alam daerah jajahan. Kemudian kepentingan politik ini masih kita rasakan sampai sekarang ini.

4) Motivasi Ilmu Pengetahuan dan Kajian Ilmiah

Motivasi ini hanya dimiliki sebagian kecil golongan barat yang betul-betul ingin mengetahui kebudayaan, agama, dan bahasa setiap umat. Bahkan di antara golongan yang mencintai keilmuan pun ada yang melenceng dan bersikap subyektif dalam memahami Islam dan warisannya. Karena ada motif lain yang mereka emban, yakni melakukan tipu daya dan pendistorsian kebenaran. Kecuali mereka yang memperoleh hidayah dari Allah, mengimaninya dibarengi dengan kajiannya yang penuh ikhlas tanpa disertai hawa nafsu. ${ }^{5}$

\section{b. Sekilas Tentang Agama Yahudi}

Sebelum membahas lebih jauh tentang Abraham Geiger, maka penting mengemukakan sekilas tentang agama Yahudi, karena Abraham Geiger merupakan penganut Yahudi yang kuat.

Agama Yahudi yang sering diartikan dengan istilah Judaism, dalam Jewish Encyclopedia diartikan sebagai "sesuatu bentuk hidup yang berdasarkan kepada kebapakan Tuhan serta wahyu-Nya. Istilah Judaism mengandung pengertian tentang eksistensi seperangkat kepercayaan dan kebiasaan yang membentuk Judaisme dan menciptakan ketaatan yang membuat seorang menjadi Yahudi. ${ }^{6}$ Sementara itu, bagi orang Islam, Yahudi cenderung diartikan sebagai agama yang diturunkan Tuhan kepada Nabi Musa as. sebagai nabi dengan Taurat sebagai kitab sucinya. ${ }^{7}$

\footnotetext{
${ }^{3}$ Mustafa Al-Siba'i, Al-Istisyraq Wa Al-Mustasyriqun ma Labum wa Ma 'Alaibim, Dar al-Warraq, dalam Maktab asySyamilah, h. 17

${ }^{4}$ Muhammad al-Bahiy, Al-Mubasyirun wa al-Mustasyriqun fi Manqifibim min al-Islam, dalam Maktabah Syamilah, h. 6 ${ }^{5}$ Mustafa Al-Siba'i, Al-Istisyraq Wa Al-Mustasyriqun ma Labum wa Ma 'Alaibim, Dar al-Warraq, dalam Maktab asySyamilab, h. 25.

${ }^{6}$ Ismail Razy al-Faruqi, Trialog Tiga Agama Besar, (Surabaya: Pustaka Progresif, 1997), h. 43.

${ }^{7}$ Burhanuddin Daya, Agama Yahudi. (Yogyakarta: PT. Bagus Arafah, 1982), h. 2.
} 
Sebagai suatu agama monotheisme, Yahudi tidak hanya sebagai agama dan kepercayaan, tetapi merupakan suatu kekuatan yang ingin menyatakan dirinya sebagai suatu agama tertua di dunia, berasal dari Ibrahim sebagai pioner dari dua agama besar lainnya, yaitu Islam dan Masehi. ${ }^{8}$ Dalam agama Yahudi, terdapat nabi-nabi yang dikenal sebagai nabi Israel, para pendeta atau rabbi, para rahib yang memiliki peran penting dalam pembinaan agama sepanjang sejarahnya. Selain itu, ada beberapa kitab yang dianggap suci oleh agama Yahudi seperti Torah, Talmud, Septaguinta, dan Pentateuch. Dari kitab-kitab ini, yang menjadi kitab inti adalah Taurat atau The Old Testament. ${ }^{9}$

\section{Abraham Geiger dan Konstruksi Pemikirannnya Tentang Al-Qur`an \\ a. Layout Historis-Biografis Abraham Gaiger}

Abraham Geiger lahir pada tahun 1810. Merupakan tokoh reformasi Yahudi yang memulai geraknya di Breslau, Frankfurt, dan Berlin. ${ }^{10}$ Pada usia 17 tahun, Geiger sudah aktif dengan mengambil bagian dalam menulis Mishnah, perbedaan hukum Talmud dengan Bible, dan Kamus Bahasa Ibrani-Mishnaic. Pada bulan april 1829 Geiger memulai kuliah di University of Heidelberg. Di sana ia banyak belajar filologi, arkeologi, filsafat, dan studi Bible. Setelah menjalani satu semester ia memilih pindah ke University of Bonn. Di tempat tersebut ia bersama rekan-rekannya mengikuti kelompok pemuda Yahudi yang dipersiapkan untuk menjadi Rabbi. Terbukti kemudian ia masuk dan ditunjuk sebagai Rabbi di kota Wiesbaden pada tahun 1832.

Ia mengkaji intensif mengenai dunia timur dan kemudian keseriusannya ia tuangkan dalam karya "Was hat Mohammed aus dem Judenthume aufgenommen?". Tulisan ini memenangi kontes essay serta melambungkan namanya sebagai pakar dunia Timur. Dengan tulisan ini pula ia meraih gelar Ph.D di University of Marburg. Tulisan tersebut pula yang kemudian menjadi magnumopus-nya mengenai tentang historis kritis terhadap konsepsi origin al-Qur'an. Dikenal sebagai reformis Yahudi, Geiger bersama dengan gurunya Leopold Zunz (1794-1886) berupaya melakukan reformasi di tubuh Yahudi untuk keluar dari konsep agama ritualis. Geiger juga menjadi pelopor pengakuan kedudukan wanita dalam ruang sosial dan ritual yang sebelumnya teralienasi dalam tradisi Yahudi. Ia bersama David Einhorn berupaya membuka ruang publik bagi wanita dan menyebarkan gagasan kebebasan wanita yang sebelumnya dianggap mengalami degradasi. Dengan pandangan liberal tersebut, pada tahun 1838 idealitas Geiger diserang oleh kelompok Yahudi ortodok serta Geiger disuruh untuk melepas gelar Rabbi-nya. Untuk itu ia pindah ke Breslau. Di tempat barunya ini, pergerakan idealitas Geiger bukannya melemah, malah semakin kuat. Ia secara gencar menyerang Ritual dan tradisi Yahudi ortodok seperti tradisi dietary (diet mengurangi makan), memakai kippah (peci yahudi), memakai tallit (selendang ibadah), serta melepaskan tafillin (Rumbai Ikat Kepala). Ia melihat hal-hal semacam itu kontraproduktif atau kesia-siaan belaka. ${ }^{11}$

Bersama Samuel Holdheim ia membangun konsep masyarakat Yahudi sosialis, modern, dan terintegrasi. Ia mencoba merancang regulasi dalam menata identitas dan standar masyarakat Yahudi sebagai bagian dari masyarakat perkotaan sebagai kelompok jaringan Yahudi global. Setelah bersusah payah meniti prestasi dalam dunia akademis dan setelah menunaikan apa yang ia asumsikan sebagai sebuah perjuangan

\footnotetext{
${ }^{8}$ Burhanuddin Daya, Agama Yabudi, h. 2.

${ }^{9}$ Mujahid Abdul Manaf, Sejarah Agama-Agama (Jakarta: PT. Raja Grafindo Persada, 1996), h. 55.

${ }^{10}$ Ken Spiro, The Reform Movement: Crash course in Jewis History. (Jewish Pathways, 2008), h. 5.

${ }^{11}$ Cornelia Wilhelm, The Independent Orders of B'nai B'rith and True Sisters. (Michigan: Wyne State University Pres Detroit, 2011 ), h. 42.
} 
reformasi Yahudi sosialis, akhirnya Abraham Geiger menghembuskan nafas terakhirnya di Berlin pada tahun $1874 .^{12}$

\section{b. Karya-karyanya}

Di antara beberapa karya Geiger adalah : 1) Was hat Mohammed aus dem Judentume aufgenommen? Bonn, 1833 (translated as Judaism and Islam: A Prize Essay, F. M. Young, 1896). 2) Das Judenthum und seine Geschichte von der Zerstörung des zweiten Tempels bis zum Ende des zwölften Jahrhunderts. In zwölf Vorlesungen. Nebst einem Anhange: Offenes Sendschreiben an Herrn Professor Dr. Holtzmann. Breslau: Schletter, 1865-71(translated as Judaism and its history: in 2 parts, Lanham [u.a.]: Univ. Press of America, 1985. ISBN 0-8191-4491-6). 3) Nachgelassene Schriften. Reprint of the 1875-1878 ed., published in Berlin by L. Gerschel. Bd 1-5. New York: Arno Press, 1980. ISBN 0-405-12255-1. ${ }^{13}$

\section{c. Potret Pemikiran Geiger Tentang Al-Qur`an}

Deskripsi pemikiran Abraham Geiger tentang al-Qur`an terlihat dalam bukunya Judaism and Islam, Geiger menjelaskan bahwa al-Qur'an terpengaruh oleh agama Yahudi dalam hal-hal berikut : (1) linguistik, keimanan dan doktrin, (2) peraturanperaturan hukum dan moral, (3) pandangan tentang kehidupan, dan (4) cerita-cerita dalam al-Qur'an. Berikut beberapa deskripsi pemikrian Geiger tentang keterpengaruhan al-Qur`an dari Tradisi Yahudi. ${ }^{14}$

1) Linguistik. Al-Qur'an Yang Berasal Dari Tradisi Yabudi

Menurut Geiger, ada 14 kosa kata Al-Qur'an ${ }^{15}$ yang diadopsi dari bahasa Ibrani, di antaranya; sakinah, taagut, ${ }^{16}$ furqan, ma'un, masani, malakut ${ }^{17}$, darasa, ${ }^{18}$ tabut, jannatu 'and, ${ }^{19}$ taurat, jahannam ${ }^{20}$, rabbani, ${ }^{21}$ sabt, dan abbar.

\section{Tabut}

Geiger mengatakan bahwa akhiran " $u t$ " dalam kata ini merupakan bukti bahwa itu bukan berasal dari bahasa Arab, melainkan dari bahasa Ibrani asli yang berkenaan

${ }^{12}$ Sara E. Karesh dan Mitchell M. Hurvitz, Encyclopedia of Judaism. (New York, Facts on File, 2006), h. 168.

${ }^{13}$ Di antara karya-karya Barat yang mengkai Abraham Geiger adalah: 1) Susannah Heschel: Abraham Geiger and the Jewish Jesus. Chicago; London: Univ. of Chicago Press, 1998. (Chicago studies in the history of Judaism). ISBN 0-226-32959-3. 2) Ludwig Geiger: Abraham Geiger. Leben und Werk für ein Judentum in der Moderne. Berlin: JVB, 2001. ISBN 3-934658-20-2. 2) Christian Wiese (ed.) Jüdische Existenz in der Moderne: Abraham Geiger und die Wissenschaft des Judentums (German and English), de Gruyter, Berlin 2013, ISBN 978-3-11-024759-6. 3) Hartmut Bomhoff: Abraham Geiger-durch Wissen zum Glauben-Through reason to faith: reform and the science of Judaism. (Text dt. und engl.). Stiftung Neue Synagoge Berlin, Centrum Judaicum. Jüdische Miniaturen ; Bd. 45. Berlin: Hentrich und Hentrich 2006. ISBN 3-938485-27-2 4) Jobst Paul (2006): "Das ,Konvergenz'-Projekt - Humanitätsreligion und Judentum im 19. Jahrhundert". In: Margarete Jäger, Jürgen Link (Hg.): Macht - Religion - Politik. Zur Renaissance religiöser Praktiken und Mentalitäten. Münster 2006.ISBN 3-89771-740-9. 5) Heschel (2007). "Geiger, Abraham". In Berenbaum, Michael; Skolnik, Fred. Encyclopaedia Judaica. 7 (2nd ed.). Detroit: Macmillan Reference USA. pp. 412-415. ISBN 9780028660974. Retrieved 4 November 2013. From Wikipedia, the free encyclopedia, 9 Desember 2018.

${ }^{14}$ Kajian ini dirangkum dari bacaan atas Abraham Geiger, Judaism and Islam. (New York : Pusblishing House, 1989), h. 41-72.

${ }^{15}$ Dari 14 kosa kata yang dikaji oleh Geiger, 6 di antaranya juga pernah dikaji oleh as-Suyuti dalam kitab al-Itqan fi 'Ulum Qur'an. (Beirut: Dar al-Fikr, 2008), h. 198.

${ }^{16}$ Menurut as-Suyuti, kata tersebut berasal dari bahasa Habasyiah, yang berarti 'dukun'. Lihat as-Suyuti, al-Itqan fi 'Ulum Qur'an, h 198.

${ }^{17}$ Maknanya "Malaikat-malaikat" berasal dari bahasa Nabathea. As-Suyuti, al-Itqan fi 'Ulum Qur'an, h. 199.

${ }^{18}$ Maknanya "Mereka saling membaca” menurut umatYahudi, as-Suyuti, al-Itqan fi 'Ulum Qur'an, h. 197.

${ }^{19}$ Kata tersebut berasal dari bahasa Romawi. As-Suyuti, al-Itqan fi 'Ulum al-Qur' an, h. 198.

${ }^{20}$ Sebagai mengatakan bahasa ini berasal dari bahasa Persia dan Ibrani. As-Suyuti, al-Itqan fi 'Ulum Qur'an, h. 197.

${ }^{21}$ Sebagaian mengatakan kata ini berasal dari kata Ibrani, namun ada juga yang mengatakan berasal dari kata Suryaniyyah. As-Suyuti, al-Itqan fi Ulum Qur'an, h. 197. 
dengan ajaran Yahudi. Kata tabut dalam ajaran Yahudi ada dua empat. Salah satunya pada kisah Nabi Musa as. yang diletakkan ibunya kedaam perahu.

\section{Jannatu 'Adn}

Kata 'adn dalam bahasa Arab bermakna kesenangan atau kebahagiaan (nama surga). Menurut Geiger, pada dasarnya bahasa ini berasal dari Ibrani. Dalam agama Yahudi, "and" adalah nama dari suatu daerah yang telah dihuni oleh orang tua mereka, yaitu Adan dan Hawa. Bagian daerah yang mereka tempati itu berupa kebun pohon yang biasa disebut dalam Injil dengan "Taman Eden". Dalam perkembangannya, arti kata ini tidak lagi mewakili nama suatu tempat, tetapi digunakan untuk menunjukkan arti surga, meskipun dalam tataran praksisnya bangsa Yahudi masih menggunakan Taman Eden sebagai sebuah tempat juga.

\section{Jahannam}

Kata in juga diklaim berasa dari Yahudi. Kata "Jahannam" mengacu pada lembah Hinnom, yaitu suatu lembah yang penuh dengan penderitaan. Karena simbol dari penderitaan, kemudian mendorong penggunaan binnom menjadi gehinnom dalam kitab Talmud untuk menandakan neraka.

\section{Rabbani}

Kata ini dianggap berasal dari Yahudi karena akhiran "an" pada kata "rabb", yang berarti Tuhan kita atau guru. Menurut Geiger, akhiran "an" seperti itu adalah hal yang biasa dalam bahasa Yahudi yang bermakna pendeta (rahib), seperti pada kata; rabban dan rubban.

\section{Sabt}

Kata ini digunakan untuk menunjukkan hari sabtu (hari akhir pekan) oleh Islam, Yahudi, dan Kristen. Dalam kitab Eksodus XVI: I, Ben Ezra memberikan pandangannya bahwa dalam bahasa Arab ada 5 hari yang diberi nama sesuai urutan angka, yaitu hari pertama (ahad), hari kedua (isnin), hari ketiga (sulasa'u), hari keempat (arbi'a'u), hari kelima (kbamis). Tetapi dihari keenam tidak demikian. Justru Islam menggunakan kata "sabt", dan dianggap hari yang suci dalam seminggu. Oleh karena itu, menurutnya, kata "sabbat" dalam bahasa Arab Shin yang dilafalkan seperti Samech dalam bahasa Ibrani dipertukarkan ke dalam bahasa mereka.

\section{Taurat}

Maknanya hukum. Kata ini hanya digunakan untuk tradisi pewahyuan dalam agama Yahudi. Nabi Muhammad dengan tradisi oralnya tidak bisa membedakan perbedaan makna kata ini secara pasti. Bahkan Nabi Muhammad memasukkan makna "Pentatukh" dalam kata ini. ${ }^{26}$

2) Konsep Agama Islam

Keimanan Dan Doktrin Keagamaan

Abraham Geiger menganggap ada beberapa aspek keimanan dan doktrin keagamaan yang diadopsi Nabi Muhammad dari ajaran sebelum Islam, seperti;

Pertama, tentang penciptaan langit dan bumi beserta segala isinya dalam enam hari. Ia mengatakan bahwa dalam hal ini pemikiran Nabi Muhammad sejalan dengan ajaran Bibel. Namun di ayat lain, Nabi Muhammad juga mengatakan bahwa bumi diciptakan selama dua hari. Ayat ini menurut Abraham, kontradiktif dengan ayat pertama. Maka dari itu, ia menganggap Nabi Muhammad sangat sedikit pengetahuannya tentang Bibel, sehingga akhirnya tidak sejalan lagi.

Selanjutnya, ia mengatakan bahwa meskipun Nabi Muhammad mengakui adanya hari ke-tujuh, yaitu sabt, tapi Nabi Muhammad tidak mau mengakui kesakralan (kesucian) hari tersebut. Menurutnya, Nabi Muhammad telah menyinggung persaan

${ }^{26}$ Abraham Geiger, Judaism and Islam, h. 32 
umat Yahudi dan menolak kepercayaan mereka tentang Tuhan yang beristirahat pada hari ke-tujuh tersebut. ${ }^{23}$

Kedua, Tujuh tingkatan surga. Dalam kitab suci disebutkan bahwa ada tujuh tingkatan surga dan semuanya telah diberi nama. Hal ini tertera dalam Chagiga $9: 2$. Begitu juga dalam Al-Qur'an juga terdapat pernyataan Nabi Muhammad juga menyebutkan hal yang sama, seperti dalam Qs. al-Baqarah [2] : $29{ }^{24}$

Ketiga, Kepercayaan tentang pembalasan di hari akhir. Orang Yahudi percaya tenang hal ini, begitu juga tentang balasan surga dan neraka. Geiger mangatakan bahwa ternyata bahwa hal ini juga muncul dalam agama Islam. Dalam Isaiah, v. 14, disebutkan bahwa penguasa neraka setiap hari bertanya, "Berikan kami makanan, agar kami merasa puas". Dalam Al-Qur'an juga terdapat pernyataan yang sama, meski dengan redaksi yang sedikit berbeda, yaitu dalam Qs. Qaf [50] : 30. ${ }^{25}$

Selain itu, kepercayaan tentang Yajuj dan Ma'juj. Malaikat dalam kubur, perumpamaan orang saleh, dan lain sebagainya. ${ }^{26}$

3) Aturan bukum dan moral

Yahudi kaya akan ajaran tunggal, dan Nabi Muhammad dianggap telah meminjam ajaran ini, di antaranya;

a) Shalat (sembahyang).

Ada beberapa aspek dalam ibadah shalat yang dianggap Geiger sama dengan ajaran Yahudi, yaitu: (1). Kansep shalat khauf. Menurutnya, Nabi Muhammad itu seperti rabbi yang menentukan posisi berdiri bagi ibadah shalat. Seperti dikutip Geiger dari perkataan Nabi Muhammad, "berdirilah ketika menghadap Tuhanmu, tetapi jika kamu takut, lakukanlah (shalat) sambil berjalan atau berkendaraan". ${ }^{27}$ Tiga posisi ini juga terdapat dalam surat X. 13. Dengan kata lain, konsep shalat dalam kondisi berbahaya atau peperangan (saat khauf) terdapat dalam agama Yahudi dan juga Islam. Kesamaan inilah yang dianggap Geiger sebagai “peminjaman” tradisi. (2) Larangan shalat bagi yang mabuk. Terkait kondisi genting yang disebut pada poin pertama, konsentrasi dalam menjalankan shalat menjadi hal yang urgen bagi seorang Muslim. Maka dari itu, manurut Geiger, Nabi Muhammad melarang umatnya untuk tidak menjalankan ibadah shalat dalam keadaan mabuk. Larangan ini juga terdapat dalam ajaran Talmud. (3) Legitimasi Tayammum. Dalam ajaran Talmud, air adalah salah satu sarana untuk bersuci.

${ }^{23}$ Abraham Geiger, The Origins of the Koran. (New York: Prometheus Books, 1998), h. 174.

${ }^{24}$ Abraham Geiger, The Origins of the Koran, h. 174.

${ }^{25}$ Qs. Al-Baqarah [2] : 29 :

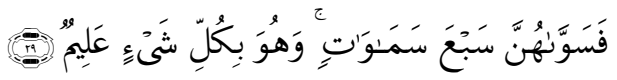

“... lalu dijadikan-Nya tujuh langit. dan Dia Maha mengetahui segala sesuatu."

${ }^{26}$ Qs. Qaf [50] : 30:

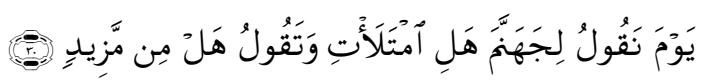

"(dan ingatlah akan) hari (yang pada hari itu) Kami bertanya kepada Jahannam : "Apakah kamu sudah penuh?" Dia Menjawab : "Masih ada tambahan?"

${ }^{27}$ Qs. Al-Baqarah [2] : 238-239:

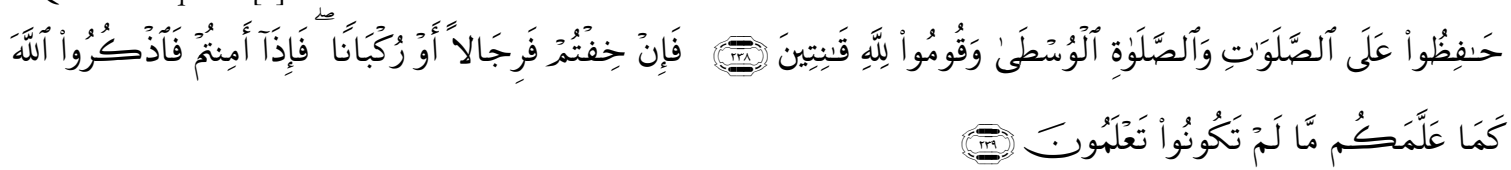

"Peliharalah semua shalat(mu), dan (peliharalah) shalat wustha Berdirilah untuk Allah (dalam shalatmu) dengan khusyu'. Jika kamu dalam Keadaan takut (bahaya), Maka Shalatlah sambil berjalan atau berkendaraan. kemudian apabila kamu telah aman, Maka sebutlah Allah (shalatlah), sebagaimana Allah telah mengajarkan kepada kamu apa yang belum kamu ketahui. 
Bila tidak ada air, maka pasir bisa menjadi alternatif utama. Begitu juga halnya dalam agama Islam, yang memperbolehkan tayammum sebagai sarana bersuci. ${ }^{32}$

Selain tiga poin di atas, ada juga konsep ajaran Islam lainnya yang dianggap Geiger diadopsi dari agama Yahudi, seperti; batalnya wudu ketika menyentuh perempuan, etika shalat berjamaah, dan aturan dalam ibadah puasa.

Aturan agama terkait perempuan, seperti; durasi masa iddah selama tiga bulan dan durasi menyusui selama dua tahun.

\section{Pandangan Hidup}

Menurut Geiger, ada beberapa hal yang sama antara Islam dan Yahudi dari aspek pandangan hidup, seperti;

a. Harapan menjadi husnul khatimah (meninggal dalam keadaan baik). Dalam A-Qur'an disebut, (wa tawaffana ma'al abrar). ${ }^{28}$ Begitu juga dalam Balaam, "Let me die the death of the righteous". ${ }^{29}$

b. Etika saat membuat janji. Dalam Islam seseorang dianjurkan mengucapkan "Insya Allah" ketika berjanji untuk melakukan sesuatu. ${ }^{30}$ Begitu juga dalam ajaran Yahudi.

c. Yahudi mengenal adanya balasan kebaikan. Hal ini disebut dalam Baba Kamma. 92. Hal ini juga senada dengan Qs. An-Nisa [4] : 85. ${ }^{31}$

d. Amal Jariyah. Dalam ajaran Yahudi disebutkan bahwa ketika seorang meninggal maka ia kan meninggalkan semuanya, kecuali amal ibadahnya. Begitu juga dengan hadis Nabi Saw. pernah mengatakan hal yang sama bahwa tiga hal yang akan mengiringi seseorang saat kematian, dua hal akan kembali dan satu hal yang akan menemaninya. Tiga tersebut yaitu keluarga, kesuksesan dan amal kebajikan. Keluarga dan kesuksesan (duniawi) akan kembali pulang, tetapi amal kebajikan akan tetap menemaninya (di dalam kubur). ${ }^{32}$

4) Kisah-Kisah A-Qur'an Dari Tradisi Yabudi

Ada empat kategori kisah dalam al-Qur`an yang dianggap Geiger berasal dari Yahudi, yaitu : Pertama, kisah tentang kepemimpinan laki-laki (patriarchs), yaitu nabinabi yang ditulis Allah untuk umatnya, meliputi ; kisah nabi Adam hingga nabi Nuh ; kisah nabi Nuh hingga nabi Ibrahim; dan kisah nabi Ibrahim hingga nabi Musa. Kedua, kisah nabi Musa. Ketiga, tiga raja yang kekuasaannya tak terbatas, yaitu raja Thalut, nabi

${ }^{28}$ Qs. Ali Imran [3] 193 :

$$
\text { وَتَوَفَّنَا مَعَعَ ألأَبَتُرَارِ }
$$

“...Dan wafatkanlah Kami beserta orang-orang yang banyak berbakti."

${ }^{29}$ XXII : 10, dalam Abraham Geiger, Judaism and Islam, hlm. 70.

${ }^{30}$ Qs. Al-Kahfi [18] : 23-24 :

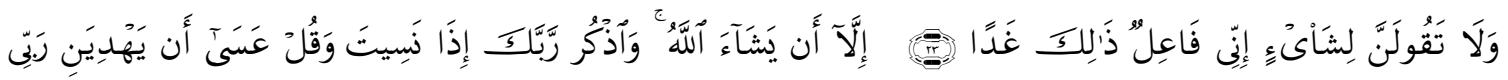

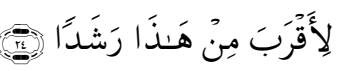

"Dan jangan sekali-kali kamu mengatakan tentang sesuatu: "Sesungguhnya aku akan mengerjakan ini besok pagi, kecuali (dengan menyebut): "Insya Allah"[879]. dan ingatlah kepada Tuhanmu jika kamu lupa dan Katakanlah: "Mudah-mudahan Tuhanku akan memberiku petunjuk kepada yang lebih dekat kebenarannya dari pada ini".

${ }^{31}$ Qs. An-Nisa [4] : 85 :

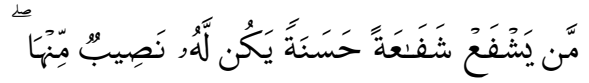

“ Barangsiapa yang memberikan syafa'at yang baik, niscaya ia akan memperoleh bahagian (pahala) dari padanya."

${ }^{32}$ Abraham Geiger, Judaism and Islam, h. 72. 
Daud, dan nabi Sulaiman. Keempat, orang-orang suci yang diutus setelah masa nabi Sulaiman. ${ }^{33}$

\section{Sekilas Posisi Kajian Abraham Geiger dalam Studi Al-Qur`an Barat}

Fazlur Rahman dalam bukunya The Major Themes of The Qur'an menyebutkan, ada tiga tipe mengenai karya-karya orientalis tentang al-Qur'an. Pertama, karya-karya orientalis yang ingin membuktikan keterpengaruhan al-Qur'an oleh tradisi Yahudi dan Kristen ; Kedua, karya-karya orientalis yang lebih menekankan pada pembahasan historisitas serta kronologis al-Qur'an, dan ketiga, karya-karya orientalis yang membahas tema-tema tertentu dalam al-Qur'an. ${ }^{34}$

Dari ketiga tipe di atas, bahwa Abraham Geiger lebih dapat digolongkan pada tipe pertama, hal ini bisa dilihat dari beberapa pemikiran Geiger yang telah dipaparkan di atas. Secara umum, isu klasik yang diangkat tipe pertama ini adalah ingin mengungkapkan bahwa al-Qur'an tidak lebih kecuali sebuah produk dan buah tangan Muhammad yang disusun berdasarkan Bibel yang sudah berkembang saat itu di Makkah. ${ }^{35}$ Dengan kata lain, melalui data-data keterpengaruhan di atas, Geiger ingin mengatakan bahwa al-Qur'an bukanlah sesuatu yang transenden, karena "terbukti" di dalamnya terdapat kombinasi dan duplikasi dari berbagai tradisi Yahudi, Nasrani bahkan Jahiliyah. Menurutnya, al-Qur'an hanyalah refleksi Muhammad tentang tradisi dan kondisi masyarakat Arab pada saat itu (simplikasi Bibel) dan karenanya ia bersifat kultural dan untransenden.

\section{Akulturasi Al-Qur'an dari Tradisi Agama Lain : Suatu Upaya Analisis Kritis}

Jika dilihat dari aspek linguistik (baca : akulturasi bahasa) kajian yang dilakukan Geiger sebenarnya juga pernah dilakukan oleh sarjana 'Ulum al-Qur'an Islam lainnya, seperti Az-Zarkasyi dalam karyanya al-Burhan fi 'Ulum al-Qur'an, As-Suyuti dalam al-Itqan fii 'Ulum al-Qur'an, Muhammad Az-Zarqani dalam Manahi al-Irfan 'Ulum al-Qur'an, dan lain sebagainya. ${ }^{36}$

Dari hasil pembacaan penulis terhadap literatur-literatur di atas, terlihat bahwa ketiganya memang mengakui peran bahasa lain dalam ayat al-Qur'an. Misalnya Imam asSuyuti, ia menyebutkan ada 120 kosa kata yang bukan berasal dari bahasa Arab. Ia mengatakan bahwa adanya berbagai kosa kata yang seperti ini di dalam al-Qur`an adalah untuk menunjukkan bahwa al-Qur'an itu mencakup imu-ilmu pendahulu maupun mereka yang akan datang kemudian. ${ }^{37}$ Untuk menguatkan argumentasinya, as-Sayuti mengutip pendapat Ibnu Naqib yang menjelaskan hal ini dengan tegas. Ibnu Naqib bertakata, "Di antara kekuasaan al-Qur'an dibandingkan dengan kitab-kitab Allah yang lain adalah al-Qur`an diturunkan dalam bahasa sebuah kaum yang diturunkan kepada mereka dan tidak ada sesuatu pun yang turun selain bahasa mereka., 39

${ }^{33}$ Abraham Geiger, What did Muhammad Borrow from Judaism, h. 185-223.

${ }^{34}$ Fazlur Rahman, Major Themes of The Qur'an. (Minneapolis Bibliotheca Islamica, 1980), hlm. 5. Lihat juga Sahiron Syamsuddin, "Memahami dan Menyikapi Metode Orientalis dalam Kajian al-Qur'an" dalam Hermeneutika al-Qur'an Mą̧ab Jogja, (Yogyakarta: Islamika: 2003), h. 76-78.

${ }^{35}$ Sahiron Syamsuddin, "Memahami dan Menyikapi Metode Orientalis dalam Kajian al-Qur'an" dalam Hermeneutika al-Qur'an Mąhab Jogja, h. 76-78.

${ }^{36}$ Baca footnote pendapat Jalaluddin as-Suyuti sebagai pembanding dalam pada pembahsan pemahaman Geiger tentang akulturasi lingusitik al-Qur`an dari tradisi Yahudi.

${ }^{37}$ As-Suyuti, al-Itqan fi 'Ulum Qur'an, hlm. 195.

${ }^{39}$ Qs. Ibrahim [14] : 4 :

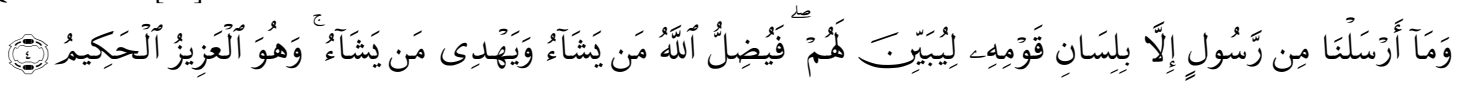

"Kami tidak mengutus seorang rasulpun, melainkan dengan bahasa kaumnya, supaya ia dapat memberi penjelasan dengan terang kepada mereka. Maka Allah menyesatkan, siapa yang Dia kehendaki, dan memberi 
Di samping itu, tantang keterpengaruhan kosa kata al-Qur'an atas bahasa asing apakah itu dari Agama Yahudi, Nasrani ataupun dari bahasa-bahasa asing lainnya, hal ini memang sudah menjadi kenyataan yang bisa dimengerti oleh masyarakat Muslim, mengingat al-Qur'an sendiri turun tidak lepas dari kondisi sosio-kultur masyarakat Arab waktu itu yang notabene bahasa-bahasa yang mereka gunakan tidaklah kesemuanya murni produk masyarakat Arab setempat, bahasa Persia dan Ibrani adalah sebagian bahasa asing yang dapat ditemui pada sebagian ayat-ayat al-Qur an dan sebenarnya hal itu sudah menjadi bahasa "Arab" (baca : Arabisasi). ${ }^{40}$ Di samping bahasa, budaya lokal pra-Islam juga terekam sebagai eksistensi al-Qur $a n^{41}$, baik itu aspek normatif-yuridis maupun empiris-praktis. Salah satu bukti normatif-yuridis, al-Qur'an yang menginformasikan agar umat Muhammad mengikuti syariat agama Ibrahim terekam dalam surat "ikutlah millah ibrabim yang hanif ${ }^{\text {*2 }}$. Dalam tradisi pemikiran Islam belakangan, pernyataan al-Qur'an ini - di samping ayat-ayat lain yang linier, diambil oleh para ahli ushul yang kemudian melahirkan cabang hukum dalam ushul fikih yang dikenal dengan "syar'u man qablana", dan hal ini menjadi salah satu legitimasi hukum Islam yang tercatat dalam literatur ushul fqh Islam. ${ }^{43}$

Sedangkan bukti-bukti empiris-praktis tradisi masyarakat Arab pra-Islam yang diikuti al-Qur'an sangat bervariasi, dan paling tidak terkait dengan tiga hal : Pertama, ritusritus peribadatan, baik warisan yang berasal dari suku Arab, seperti, penghormatan terhadap ka'bah, menjalankan ibadah haji, menghormati bulan Ramadhan, menjalankan ibadah puasa ; Kedua, ritus-ritus sosial politik, seperti jampi-jampi, pemeliharaan onta, poligami, perbudakan, ritus-ritus hukuman, seperti al-Aqilah dan al-Qasamah, ritus-ritus peperangan, seperti, seperlima bagian rampasan perang, al-Salb, Ash-Syafiyy dan ritus-ritus politik, seperti khilafah dan syura, dan ; Ketiga ritus-ritus etika, baik etika sosial maupun etika keagamaan, seperti kemurahan hati, keberanian, kesetiaan, kejujuran, kedermawanan dan kesabaran. ${ }^{44}$

Untuk mengupas keterpengaruhan al-Qur`an dengan tradisi agama pra-Islam dari sisi empiris-praktis, menjadi menarik apa yang diungkapkan oleh Muhammad Arkoun yang dikutip oleh Zuhri dikatakan bahwa bangunan tradisi keislaman terdiri dari dua konsep : Pertama, tradisi Jahiliyah yaitu suatu tradisi yang telah mapan di masyarakat yang sedang mengalami transformasi menuju masyarakat religius. Kedua, tradisi skriptual yang merupakan tradisi yang dibangun oleh masyarakat religius. Jadi, kedatangan Islam bukan langsung mendestruksi semua budaya Arab Jahiliyah. Namun, di antara pranata-pranata sosial-budaya tersebut ada yang ditolak dan ada juga yang dimodifikasi. Kebanyakan dari tradisi Jahiliyah pra-Islam dilakukan modifikasi ketika syari'at Islam datang, di antaranya

petunjuk kepada siapa yang Dia kehendaki. dan Dia-lah Tuhan yang Maha Kuasa lagi Maha Bijaksana". Lihat juga As-Suyuutii, al-Itqan fi 'Ulum Qur'an, 195.

${ }^{40} \mathrm{Nashr}$ Hamid Abu Zaid, salah satu karakter penting teks al-Qur'an adalah bahwa ia berinteraksi dengan teksteks lain yang telah ada sebelumnya. Teks-teks pra-Qur'an itu terdiri dari: 1) Teks keagamaan, seperti Taurat dan Injil, 2) Teks kultural, seperti syair dan kinanah. lihat Dalam Moh. Nur Ichwan, "Al-Qur'an Sebagai Teks “(Teori Teks dalam Hermeneutika al-Qur'an Nashr Hamid Abu Zaid” dalam Studi al-Qur'an Kontemporer. (Yogyakarta: Tiara Wacana, 2002), h. 159.

${ }^{41} \mathrm{Hal}$ ini lah yang menunjukkan kebenaran adagium bahwa al-Qur`an adalah sumber ajaran Nabi akhir zaman (Muhamamd Saw) yang mencakup atau merangkul seluruh ajaran-ajaran Nabi-nabi dan umat terdahulu.

${ }^{42}$ Qs. An-Nahl [16] : 123 :

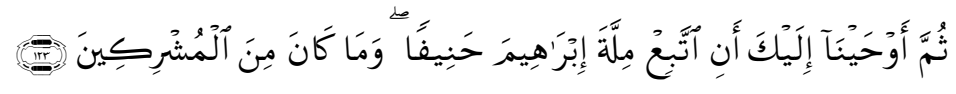

"Kemudian Kami wahyukan kepadamu (Muhammad): "Ikutilah agama Ibrahim seorang yang hanif" dan bukanlah Dia Termasuk orang-orang yang mempersekutukan tuhan."

${ }^{43}$ Lihat Abdul Wahhab Khalaf, Ushul Fiqh. (Kairo: Dar al-Qalam, 1398 H), h. 93 ; Hasbi ash-Shiddieqy, Falsafah Hukum Islam, (Jakarta: Bulan Bintang, 1993), h. 44.

${ }^{44}$ Schaich, “Al-Qur'an Dan Orientalisme; Studi Pemikiran Abraham Geiger” diakses pada 9 Desember 2018. 
seperti pada zaman Nabi Musa as. jika pakaian terkena najis makan bagian pakaian yang terkena najis tersebut harus dipotong, ketika syari'at Islam datang maka cukup dengan dicuci tanpa harus memotong pakaian tersebut, kemudian berkurban, pada zaman Jahiliyah mereka biasanya melakukan kurban dengan manusia kemudian setelah Islam datang maka diganti dengan cara yang lebih baik, akikah zaman Jahiliyah akikah - yang mana darah binatang sembelihan tersebut dilumuri ke kepala sang bayi dan setelah Islam datang tradisi tersebut dimodifikasi menjadi lebih Islami (dengan menyedekahkan daging akikahan tersebut), dan sederetan tradisi lainnya yang dikomodifikasi oleh Islam. ${ }^{45}$

\section{Simpulan}

Berdasarkan pembahasan di atas, maka dapat disimpulkan bahwa memang ada beberapa kosa kata al-Qur an yang sama dengan kosa kata dalam agama Yahudi. Terlepas dari apakah itu murni akulturasi dari bahasa Yahudi atau justru ada kesamaan antara bahasa yang digunakan oleh al-Qur`an dengan bahasa yang digunakan oleh agama Yahudi. Dan harus diakui bahwa Islam datang bukan dalam ruang vacum historis - telah banyak pranatapranata sosial masyarakat yang sudah eksis sebelum Islam muncul. Oleh karena itu, sangat mungkin adanya akulturasi bahasa, tradisi dan budaya agama lain dengan Islam sebagai agama yang datang kemudian. Walaupun demikian, hal ini tidak bisa dikatakan merubah keautentitasan al-Qur`an atau dokrin Islam, karena Islam datang bukan sebagai opposition (penentang), namun sebagai completing (penyempurnaan) bagi agama-agama sebelumnya.

\section{Daftar Pustaka}

Abdul Manaf, Mujahid. (1996) Sejarah Agama-Agama, Jakarta: PT. Raja Grafindo Persada. Ash-Shiddieqy, Hasbi, (1993). Falsafah Hukum Islam, Jakarta: Bulan Bintang.

As-Suyuti, Jalaluddin, (2008). Al-Itqan fi 'Ulum Qur'an, Beirut: Dar al-Fikri.

Daya, Burhanuddin, (1982). Agama Yahudi, Yogyakarta : PT. Bagus Arafah.

Geiger, Abraham, (1989). Judaism and Islam, New York : Pusblishing House. , (1998). The Origins of the Koran, New York : Prometheus Books.

Karesh E. Sara dan Mitchell M. Hurvitz, (2006). Encyclopedia of Judaism New York, Facts on File.

Khalaf, Abdul Wahhab, (1398H). Ushul Fiqh, Kairo : Dar al-Qalam..

Nanji, Azim. (ed), (2003). Peta Studi Islam : Orientlisme dan Arah Baru Kajian Islam Di Barat, Yogyakarta, Fajar Pustaka Baru.

Nur Ichwan, Mohammad, (2002). "Al-Qur'an Sebagai Teks" (Teori Teks dalam Hermeneutika al-Qur'an Nashr Hamid Abu Zaid" dalam Studi al-Qur'an Kontemporer, Yogyakarta: Tiara Wacana.

Rahman, Fazlur, (1980). Major Themes of The Qur'an, Minneapolis Bibliotheca Islamica.

Razy al-Faruqi, Ismail, 91997). Trialog Tiga Agama Besar, Surabaya: Pustaka Progresif.

Saenong, B. Ilham, (2002). Hermeneutika Pembebasan: Metodologi Tafsir Al-Qur'an Menurut Hassan Hanafi, Jakarta: Mizan.

Spiro, Ken, (2008). The Reform Movement : Crash course in Jewis History, Jewish Pathways.

Syamsuddin, Sahiron, (2003). "Memahami dan Menyikapi Metode Orientalis dalam Kajian al-Qur'an" dalam Hermeneutika al-Qur'an Maz̧bab Jogja, Yogyakarta: Islamika.

Wilhelm, Cornelia, (2011). The Independent Orders of B'nai B'rith and True Sisters Michigan: Wyne State University Pres Detroit.

Zuhri, (2005). Al-Hadis Dalam Pemikiran Mubammad Arkoun, Jurnal Studi ilmu-ilmu AlQur`an, vol 6, no. 1, Januari.

45Zuhri, Al-Hadis Dalam Pemikiran Mubammad Arkoun,dalam Jurnal Studi Ilmu-Ilmu Al-Qur'an, vol 6, no. 1, Januari 2005, UIN Sunan Kalijaga: Yogjakarta, h. 121. 
Maktab asy-Syamilah.

Wikipedia/ https://en.wikipedia.org/wiki/Abraham Geiger. 